\title{
A Multi-Objective Risk Return Trade off Models for Banks: Fuzzy Programming Approach
}

\author{
Rahul Chaudhury*, Sahidul Islam \\ Department of Mathematics, University of Kalyani, Kalyani, Nadia 741235, India
}

Corresponding Author Email: rahul.math6@gmail.com

https://doi.org/10.18280/mmep.080203

Received: 22 March 2021

Accepted: 8 April 2021

\section{Keywords:}

interest rate risk, liquidity risk, duration, convexity, fuzzy programming

\begin{abstract}
The main focus of banking sector is on the risk management. Asset liability management (ALM) is one of the key processes to manage the risks. The objective of this paper is to develop a multi-objective asset liability optimization model for banks with the maximization of market value of equity and minimization of duration gap as the objective function. Several liquidity ratios, concept of duration and convexity are considered to manage the risk properly. Interest rate risk and liquidity risk are two major considerations in both the regulation and management of a bank. As we know that, with the fluctuation of the market interest rate, the market value of assets and liabilities of a bank changes and that affects a change in owner's equity. In order to overcome such type of situation here we will use the concept of duration and convexity to manage the interest rate risk. In case of liquidity risk the shortage of liquidity may also put that bank in risk and simultaneously it is very crucial to manage the cash flow properly. So here we will use some major liquidity ratios to manage the liquidity risk. We will take the help of fuzzy programming technique to solve our model properly. A numerical example is given to illustrate our model by considering a hypothetical bank balance sheet. Also we will compare the result obtained by fuzzy technique with result obtained by a non fuzzy based technique.
\end{abstract}

\section{INTRODUCTION}

Asset Liability Management (ALM) may become a crucial function to the institutions (e.g., banks, finance companies, leasing companies, and insurance companies) because of volatile global market, increase of new financial products and changing environment of regulatory system over the last few years. Being a dynamic and comprehensive framework ALM helps banks and financial institutions to measure, monitor, and manage the market risks. Basically ALM enables the institutions to take appropriate decision in a more informed framework through considering various types of risks. It maintains both assets and liabilities with the complexities of the financial market in an integrated approach.

Banks and other financial institutions basically deal with some money inflows and outflows and these exposes them to several types of risks such as liquidity risk, interest rate risk, credit risk and many other types of risks. The ALM system has various functions to manage risks, such as, liquidity risk management, market risk management, trading risk management, funding and capital planning, profit planning and growth projection, i.e., ALM is a technique that helps the institutions to deal with these risks with protection. By the ALM process an institution manages its balance sheet for alternative scenarios with different interest rate and liquidity. So ALM is a method by which the institutions take suitable strategies for management of assets and liabilities in order to measure and monitor risk.

ALM is a technique designed to hedge interest rate risk within a planned horizon, given an Interest-rate forecast. It is a dynamic process of planning, organizing and controlling of assets and liabilities and their volumes, mixes, maturities, yields and costs in order to maintain liquidity and Net Interest Income (NII).

Bank's balance sheet is the main component of the bank which gives us the view of bank's sources and its utilization. The ALM helps in strategic planning for bank in maximizing the financial health while maintaining all the risks attached with the bank's operation. Basically ALM is to draw an appropriate design of strategic management that how to invest the various assets in order to maintain the liabilities and expected outflow of the bank by using the available financial resources. In bank's ALM process bank's managers try to propose a way by which they can maximize the return and control the total risks and lastly they will be able to maximize the shareholders wealth. In our work we want to propose a model which may give satisfactory solutions and helps the bank's manager in taking the proper decision.

By reviewing previous works in this area understand that the mathematical model of bank's ALM can be partitioned into two general groups deterministic and probabilistic. For the deterministic models linear and non linear programming problem is used and for the probabilistic models the volatility of the variables and the existing uncertainties is considered.

The pioneer model of ALM is a deterministic linear programming model given by Chambers and Charnes [1]. In that paper their goal was to find an optimal portfolio of a bank over several periods and in the constraints of the model they had defined the level of present risk in banks such as level of bank's earnings, interest rates, demand deposits and term deposits.

Later on Cohen and Hammer [2], Robertson [3], Lifson and 
Blackman [4], Filitz and Loeffler [5] had also defined some ALM models in different fashions, but all of them had considered the profitability of the bank as objective function with some other linear constraints.

In some of the papers the bank management had considered several conflicting objectives such as maximization of profit, maximization of deposits and loans, minimization of risks and so that is why some authors preferred multi-objective programming problem to deal with ALM problem.

Later on Eatman and Sealey [6] developed a multiobjective model of ALM by considering objectives as net profit, capital adequacy and ratio of risk assets to capital. Giokas and Vassiloglou [7] had also developed a goal programming model for a bank's ALM, with conflicting goals of maximizing revenues and minimizing risks, which is attached with the allocation of bank's capital, retaining the bank's market share, increasing the size of bank's deposits and loans. In 2004 Kosmidou and Zopounidis [8] had developed a goal programming model with simulation analysis by taking data of a Greek commercial bank. They had considered several conflicting goals such as liquidity, solvency, returns and expansion of deposits and loans and they had also considered environmental and political constraints and uncertainty of interest rates. In the result they had shown that the major sources of the profitability of banks are the loans and the deposits.

In the paper [9] Chi, G., and Chi, F. had developed an optimization model of asset liability portfolio. In this decision making method of ALM the author had considered both the interest rate risk and liquidity risk. The regulation and operation restraints had been used for controlling the liquidity risk where as duration gap method had been used for controlling the interest rate risk. In Ref. [10] Yang and Xu in their optimal model of asset liability portfolio, their focus was only on controlling the liquidity risk. For avoiding the problem of shortage of liquidity faced by banks, they had controlled liquidity risk through the time matching of assets and liabilities and to avoid the liquidity crisis they had used the method of quantity matching. In Ref. [11] Yang and Xu had developed another similar optimization model of asset and liability management, but in this model along with the previous two method of controlling liquidity risk they had also introduced interest rate structure symmetry for bank's asset portfolio. In Ref. [12] Yan et al. in their ALM optimal model had tried to increase the net value using the duration gap with the advantageous change of interest rates. While the loss was maintained lee than monthly net interest income of the bank in case of disadvantageous change of interest rate, under a certain confidence level by setting the constraints based on Value at Risk. In Ref. [13] Wu and Chi in their bank asset and liability portfolio optimization model had used the concept of directional duration and directional convexity to immunize the interest rate risk. In paper [14] the authors focused on fluctuation and manage of interest rate risk and had considered effective duration and effective convexity as a tool to measure interest rate risk. Finally they had checked the effectiveness of the tools on a commercial bank.

The authors in Ref. [15] had employed a statistical cost accounting model to check the relationship between profit and asset liability management structure of some commercial banks of Ghana over a time period.

In Ref. [16] Tiwari and Dharmar had discussed on assetliability management problem under mean variance criterion by a general random variable related to future values of financial assets and liabilities.

In most of the deterministic models of asset liability management goal programming techniques has been used widely.

In all the optimization models of ALM mentioned above the author had taken as objective the maximization of net interest income but not only that objective full fill the actual goal of ALM. Although there are several goals of a financial institution, one of the major goals is to maximize shareholders' equity. This goal is of high priority among the other goals because if the value of the stock will not rise as per shareholder's expectations, then the current investors will not be of interest at all to carry their shares and subsequently it will be difficult for banks to raise new capital to support their future growth.

With the above observation at the background in this paper we will try to propose an asset liability optimization model which will maximize the return on equity and minimizing duration gap by putting caps on some liquidity measurable ratios in order to control the liquidity risks and the concept of convexity is used for controlling the interest rate risk. We will solve the asset liability management model using two fuzzy multi-objective program techniques namely Fuzzy Non Linear Programming technique (FNLP) and Fuzzy Additive Goal Programming technique (FAGP). Numerical examples are given to illustrate the problems by considering a hypothetical bank balance sheet. Also the model will be solved using a non fuzzy based technique namely weighted sum method. Finally the result will be compared.

\section{PREREQUISITE CONCEPTS}

Since liquidity risk and interest rate risk are two major risks for a bank, so our main aim in this paper is to control them efficiently for a bank. In this section we will discuss a little about the sources of these two types of risks and how to measure them in order to control them.

Liquidity risk and challenges can arise from an asset and funding perspective. But it needs to analyze the source of liquidity, and that will provide an understanding of how liquidity structure must be managed to ensure availability of cash resources when ever needed. So it needs a review for the sources of liquidity found in the asset and liability account as well as in the off balance sheet account. On analyzing the working procedure of a bank it will be clear that supplier and user of liquidity are intimately linked and this helps in illustrate how endogenous and exogenous forces interact and impact firm's operation.

As we normally understand that by the effect of interest rate risk, commercial banks earn money by lending, investing and borrowing financial assets in their business. Tang and Du [17] stated that interest rate risk can cause unfavourable effects on the economic value of the bank. Also as per the recommendation of the Basel committee on banking supervision (2004), it is clear that interest rate risk not only affects the economic value but also have an effect on the earning of the bank. For every financial institution and also particularly for the commercial banks one of the major objectives from the earnings, the credit ability and the financial stability have a direct relationship with the earnings of the bank. Due to unpredictable nature of the interest rate if the earnings of the bank falls then it may be threaten to the capital adequacy and also to the market confidence. In general 
we consider the total financial earnings of the bank as the net interest income, i.e. the difference of the total interest expense from the total interest income. Also the name, net interest income gives us an insight about the influence of the interest rate and the relationship with the interest rate.

There are several ways to measure interest rate risk but our focus is on Duration Gap and Convexity based approach. Below we will discuss about the basics of these two approaches and how they should be used to hedge against the interest rate risk since they are useful for our model.

\subsection{Duration gap}

Duration model is very crucial approach to analyze that the cash flows are sensitive to changes in interest rate. If there is a small change in the level of interest rates then there is a change in the economic value of a position of a bank, the measure of this percentage change is called the duration. The duration is considered as the weighted average time-to-maturity, where the weights are represented as the current values of cash-flows. So the significance of duration is that it reflects the size and timings of cash flows which occur before the contractual maturity of the financial instrument.

The formal way to calculate duration GAP is as follows.

Calculate the market value corresponding to each asset and liability item of the balance sheet using the formula: = $\sum_{t=1}^{n} \frac{C}{(1+y)^{t}}+\frac{M}{(1+y)^{n}}$. Then calculates each balance sheet item's duration using the formula $\mathrm{D}=\frac{\sum_{t=1}^{n} \frac{t C}{(1+y)^{t}}+\frac{n M}{(1+y)^{n}}}{P}$, this formula is also called Macaulay's formula. Next is to calculate the modified duration of assets and liabilities as an average of duration of each asset/debt with weight of the market value of asset/debt in the market value of the total assets/total debts using the formula is $M D A=\sum_{i=1}^{n} X_{A i} * D_{A i}$. Now to calculate the duration GAP(DGAP) using the formula $=[M D A-$ $\left.\left(M D L * \frac{L}{A}\right)\right]$. After the change in interest rate the new market value of asset is $A_{1}=A_{0}-\frac{1}{(1+k)} * D A * A * \Delta k$ and the same procedure is applicable for liabilities.

\subsection{Convexity}

In case of duration we just assume a parallel shift on the yield curve and we consider a small fluctuation in the interest rate. But for a large shift in the interest rate of the asset values, convexity is considered as a correction by the researcher and the practitioner. The threat of the negative convexity is also well known to the researcher. These applications are basically used to manage the asset portfolio. Zero duration gap strategy is considered as an immunizing strategy in order to preserve the value of the equity of a financial institution, just to ignore the condition of second order. Convexity is such a second order condition. A second order condition derived by Reddingtonin order to immunize the equity by using the dispersion values of each of assets and liabilities around their corresponding durations, and it is assumed that initial equity is zero.

We will consider the Taylor series approximation around the original interest rate $r_{0}$ for the value of a financial security.

$$
\begin{gathered}
v(r)=v\left(r_{0}\right)+\Delta r \cdot v^{\prime}\left(r_{0}\right)+\left(\frac{1}{2}\right) \cdot(\Delta r)^{2} \cdot v^{\prime \prime}\left(r_{0}\right) \\
+R_{n}
\end{gathered}
$$

where, $R_{n}$ is represented as the remaining terms in Taylor series expansion, $\mathrm{v}(\mathrm{r})$ is considered as the security value in terms of function of interest rate r, $\Delta r$ is treated as a change in the interest rate $\left(\mathrm{r}-\mathrm{r}_{0}\right)$, and $v^{\prime}\left(r_{0}\right)$ and $v^{\prime \prime}\left(r_{0}\right)$ are respectively the first and the second order derivatives of the security value with respect to $r$, evaluated at $r_{0}$. i.e.,

$$
\begin{aligned}
v^{\prime}\left(r_{0}\right) & =\left.\frac{\partial v}{\partial r}\right|_{r=r_{0}} \\
v^{\prime \prime}\left(r_{0}\right) & =\left.\frac{\partial^{2} v}{\partial r^{2}}\right|_{r=r_{0}}
\end{aligned}
$$

$\mathrm{R}_{\mathrm{n}}$ is considered to be insignificant for a second degree Taylor series expansion. The first order derivative is related to the duration and the second order derivative is related to the convexity in the above Eq. (1). Let us consider the duration as $D=-v^{\prime}(r)(1+r) / v(r)$ and the convexity as $C=$ $\left(\frac{1}{2}\right) v^{\prime \prime}(r) .(1+r)^{2} / v(r)$. Now rearranging the terms and considering the duration as $\mathrm{D}$ and convexity as $\mathrm{C}$, we can express Eq. (1) as:

$$
\Delta v=\left[-D \cdot \frac{\Delta r}{1+r}+C \cdot \frac{(\Delta r)^{2}}{(1+r)^{2}}\right] \cdot V
$$

From Eq. (2) it is clear that there is positive impact in the convexity on the changes in the security value caused by interest rate shift for any duration.

Now applying the Eq. (2) to all the assets and liabilities of a financial institution, we will obtain:

$$
\Delta A=\left[-D_{A} \cdot \frac{\Delta r_{A}}{1+r_{A}}+C_{A} \cdot \frac{\left(\Delta r_{A}\right)^{2}}{\left(1+r_{A}\right)^{2}}\right] \cdot A
$$

and

$$
\Delta L=\left[-D_{L} \cdot \frac{\Delta r_{L}}{1+r_{L}}+C_{L} \cdot \frac{\left(\Delta r_{L}\right)^{2}}{\left(1+r_{L}\right)^{2}}\right] \cdot L
$$

Here $r_{A}$ and $r_{L}$ is denoted as the interest rate for each of the assets and liabilities, respectively. Now considering $\Delta E=$ $\Delta A-\Delta L$, and using Eqns. (3) and (4) we will obtain:

$$
\Delta E=-D G A P \cdot A \cdot \frac{\Delta r_{A}}{1+r_{A}}+C G A P \cdot A \cdot \frac{\left(\Delta r_{A}\right)^{2}}{\left(1+r_{A}\right)^{2}}
$$

The duration gap and convexity gap are respectively denoted by DGAP and CGAP.

From Eq. (5) it is clear that if duration gap is set equal to zero, then it is not sufficient to immunize the value of equity for shifts in interest rates. Now considering $\mathrm{DGAP}=0$, the Eq. (5) will reduce to:

$$
\Delta E=C G A P \cdot A \cdot \frac{\left(\Delta r_{A}\right)^{2}}{\left(1+r_{A}\right)^{2}}
$$

If duration gap is considered to be zero, then the financial institution must make sure that the non-negative convexity gap; otherwise, zero duration gap may be treated as a way to loss. 


\section{THE MATHEMATICAL FORMULATION OF THE PROPOSED ALM MODEL}

We will now discuss about the proposed ALM model. The decision variables of the proposed model are discussed below.

\subsection{Decision variables for assets and liabilities}

Asset Side

- $\quad$ Cash and balances with Reserve Bank of India: $X_{1}(t)$.

- Balance with bank and money at call or short notice: $\mathrm{X}_{2}(\mathrm{t})$.

- Investments: $\mathrm{X}_{3}(\mathrm{t})$.

- Loans: $\mathrm{X}_{4}(\mathrm{t})$.

- Fixed Asset: $\mathrm{X}_{5}(\mathrm{t})$.

- Other Asset: $\mathrm{X}_{6}(\mathrm{t})$.

Liability Side

- $\quad$ Equity capital: $\mathrm{Y}_{1}(\mathrm{t})$.

- $\quad$ Reserve and Surplus: $\mathrm{Y}_{2}(\mathrm{t})$.

- Deposit: $\mathrm{Y}_{3}(\mathrm{t})$.

- Borrowings: $\mathrm{Y}_{4}(\mathrm{t})$.

- Other Liabilities: $\mathrm{Y}_{5}(\mathrm{t})$.

Because we have to tackle with different interest rate sensitive asset and liabilities for different time periods so for the sake of generalization we further divide the variables investment, loans, deposits and borrowings into subparts depending on several time intervals.

$$
\text { Investment } \mathrm{X}_{3}(\mathrm{t})=\left\{\begin{array}{l}
X_{3}(t, \underline{t+i}) \\
X_{3}(t, \overline{\overline{t+i}})
\end{array}, \text { where } X_{3}(t, \underline{t+i})\right. \text { is }
$$
investment return computed at time $t$ which is maturing during the period from $\mathrm{t}$ to $\mathrm{t}+\mathrm{i}$ and $X_{3}(t, \overline{t+i})$ is investment return computed at time $\mathrm{t}$ which will mature beyond time $\mathrm{t}+\mathrm{i}$.

Loans $X_{4}(t)=\left\{\begin{array}{l}X_{4}(t, \underline{t+i}) \\ X_{4}(t, \overline{t+i})\end{array}\right.$, where $X_{4}(t, \underline{t+i})$ is loan return computed at time $t$ which is maturing during the period from $\mathrm{t}$ to $\mathrm{t}+\mathrm{i}$ and $X_{4}(t, \overline{t+i})$ is loan return computed at time $\mathrm{t}$ which will mature beyond time $\mathrm{t}+\mathrm{i}$.

Borrowings $Y_{4}(t)=\left\{\begin{array}{l}Y_{4}(t, \underline{t+i}) \\ Y_{4}(t, \overline{t+i})\end{array}\right.$, where $Y_{4}(t, \underline{t+i})$ is the borrowings computed at time $\mathrm{t}$ which is due for repayment during the period from $\mathrm{t}$ to $\mathrm{t}+\mathrm{i}$ and $Y_{4}(t, \overline{t+i})$ is the borrowings computed at time $t$ which is due for repayment during the period from $\mathrm{t}$ to the period beyond the period $\mathrm{t}+\mathrm{i}$.

Deposits $Y_{3}(t)=\left\{\begin{array}{l}Y_{3}(t, \underline{t+i}) \\ Y_{3}(t, \overline{t+i})\end{array}\right.$, where $Y_{3}(t, \underline{t+i})$ is the borrowings computed at time $\mathrm{t}$ which is due for repayment during the period from $\mathrm{t}$ to $\mathrm{t}+\mathrm{i}$ and $Y_{3}(t, \overline{t+i})$ is the borrowings computed at time $t$ which is due for repayment during the period from $\mathrm{t}$ to the period beyond the period $\mathrm{t}+\mathrm{i}$.

Let us denote the total asset by A and total liability by L.

Then,

$$
\begin{aligned}
A=X_{1}(t)+X_{2}( & t)+X_{3}(t, \underline{t+i})+X_{3}(t, \overline{t+i}) \\
+ & X_{4}(t, \overline{t+i})+X_{4}(t, \overline{t+i}) \\
& +X_{5}(\mathrm{t})+\mathrm{X}_{6}(\mathrm{t})
\end{aligned}
$$

and

$$
\begin{aligned}
L=Y_{1}(t)+Y_{2}(t) & +Y_{3}(t, \underline{t+i})+Y_{3}(t, \overline{t+i}) \\
& +Y_{4}(t, \underline{t+i})+Y_{4}(t, \overline{t+i}) \\
& +Y_{5}(t)
\end{aligned}
$$

The following notations have been used in the methodology developed below

- $r_{i}$ is average yield of the $i$-th asset.

- $\mathrm{s}_{\mathrm{j}}$ the average yield of the $\mathrm{j}$-th liability.

- $\mathrm{DX}_{\mathrm{i}}$ is the duration of the $\mathrm{i}$-th asset.

- $\quad D Y_{j}$ is the duration of the $\mathrm{j}$-th liability.

- $\mathrm{CX}_{\mathrm{i}}$ is the convexity of the $\mathrm{i}$-th asset.

- $\quad \mathrm{CY}_{\mathrm{j}}$ is the convexity of the $\mathrm{j}$-th liability.

- $\quad \mathrm{k}$ and $\mathrm{m}$ are respectively the number of assets and number of liabilities in the bank balance sheet.

- $\Delta \mathrm{r}_{\mathrm{i}}$ and $\Delta \mathrm{s}_{\mathrm{j}}$ are changes in the yield rate of the i-th asset and $\mathrm{j}$-th liability respectively.

- $\mathrm{k}_{1}$ to $\mathrm{k}_{10}$ are liquidity limit set by bank, which will be of known value.

\subsection{The proposed model}

Our proposed model is

$$
\begin{aligned}
& \text { Maximize } \\
& \frac{\sum_{i=2}^{4} r_{i} X_{i}(t)-\sum_{j=2}^{4} s_{j} Y_{j}(t)+\left(\begin{array}{c}
X_{1}(t) \\
+X_{5}(t)+X_{6}(t)
\end{array}\right)}{-\left[Y_{1}(t)+Y_{5}(t)\right]}
\end{aligned}
$$

$$
\sum_{j=1}^{m} D Y_{j} \times Y_{j} \times \Delta s_{j}-\sum_{i=1}^{k i n i m i z e} D X_{i} \times X_{i} \times \Delta r_{i}
$$

Subject to

$$
\begin{gathered}
X_{1}(t)+X_{2}(t)+X_{3}(t, \underline{t+1)} \\
\frac{+X_{4}\left(t, \underline{t+1)}-Y_{3}(t, \underline{t+1})-Y_{4}(t, \underline{t+1})\right.}{A} \geq k_{1}
\end{gathered}
$$

$$
\frac{X_{1}(t)+X_{2}(t)+X_{3}\left(t, \underline{t+1)}+X_{4}(t, \underline{t+1)}\right.}{Y_{3}(t, \underline{t+1})+Y_{4}(t, \underline{t+1})} \geq k_{2}
$$$$
\frac{Y_{3}(t, \underline{t+1})+Y_{4}(t, \underline{t+1})}{Y_{1}(t)} \leq k_{3}
$$$$
\frac{Y_{3}(t, \underline{t+i})+Y_{3}(t, \overline{t+i})}{Y_{4}(t, \underline{t+i})+Y_{4}(t, \overline{t+i})} \leq k_{4}
$$$$
\frac{X_{4}(t, \underline{t+i})+X_{4}(t, \overline{t+i})}{Y_{3}(t, \underline{t+i})+Y_{3}(t, \overline{t+i})} \leq k_{5}
$$$$
\frac{Y_{1}(t)}{A} \leq k_{6}
$$

$$
\begin{gathered}
X_{2}(t)+X_{3}(t, \underline{t+i}) \\
\frac{+X_{3}(t, \overline{t+i})+X_{4}(t, \underline{t+i})+X_{4}(t, \overline{t+i})}{Y_{3}(t, \underline{t+i})+Y_{3}(t, \overline{t+i})} \geq k_{7} \\
+Y_{4}(t, \underline{t+i})+Y_{4}(t, \overline{t+i}) \\
X_{3}(t) \leq k_{8} \% \text { of } A \\
X_{4}(t) \leq k_{9} \% \text { of } A
\end{gathered}
$$




$$
\begin{gathered}
\sum_{j=1}^{m} D Y_{j} \times Y_{j} \times \Delta s_{j}-\sum_{i=1}^{k} D X_{i} \times X_{i} \times \Delta r_{i}>0 \\
\frac{1}{2} \sum_{i=1}^{k} C X_{i} \times X_{i} \times\left(\Delta r_{i}\right)^{2} \geq \frac{1}{2} \sum_{j=1}^{m} C Y_{j} \times Y_{j} \times\left(\Delta s_{j}\right)^{2}
\end{gathered}
$$

$$
\mathrm{A}=\mathrm{L}
$$

$$
A_{i} ; L_{j} \geq 0
$$

Some definitions are required to describe the model, those are discussed below

Current Asset: Current asset is simply the sum of the cash, marketable securities available within 1 year. i.e. this is liquid money hold by the bank itself and the money available within short time period.

Current Liability: Current liability is sum of short term debt obligations and the short portion of long term debt. i.e. it is basically the money which the banks have to spend within short time period.

Working Capital: Working capital is simply the difference of current asset and current liability.

\subsection{Descriptions of the objective and the constraints}

Objectives: Though there are several goals of a financial institution, one of the major goals is to maximize shareholders' equity. This goal is of high priority among the other goals because if the value of the stock will not rise as per shareholder's expectations, then the current investors will not be interest at all to carry their shares and subsequently it will be difficult for banks to raise new capital to support their future growth.

But from the view point of profitability we have set our goals as maximizing the Return on Equity (ROE). ROE actually the rate of return flowing to shareholders, i.e. the net benefit the shareholders will obtain for investing their capital in the banks.

Return on Equity $(\mathrm{ROE})=\mathrm{Net}$ Income/Total Equity Capital $=($ Total Revenue-Total Operating Expenses $) /$ Total Equity Capital.

Duration gap management is very crucial approach to analyze that the cash flows are sensitive to changes in interest rate. If there is a small change in the level of interest rates then there is a change in the economic value of a position of a bank, the measure of this percentage change is called the duration. The duration is considered as the weighted average time-tomaturity, where the weights are represented as the current values of cash-flows. So the significance of duration is that it reflects the size and timings of cash flows which occur before the contractual maturity of the financial instrument. Among several methods to mitigate interest rate risk, duration gap is very crucial one. Duration gap method is used completely to immunize the portfolio by the matching of gain and losses in the value of asset with the gain and losses in the value of the liability due to changes in interest rates.

But completely immunized duration gap model is also not very much appropriate since in a completely immunized system we can't be able to take advantages of movement of market interest rate in positive direction.

That's why instead of constructing a fully immunized ALM model we had tried to minimize the duration gap. We had considered duration gap as an index to measure risk.

Constraints: The first constraint is constraint of maintaining working capital ratio. Working capital ratio is simply working capital divided by total assets. It represents whether a bank is becoming more or less liquid as the bank grows or contracts. The bank must expect that it will increase over time so that banks have to put a lower limit to this ratio in order to maintain a minimum ratio.

The second constraint is for maintaining the Current Ratio of the banks. Current Ratio is Current asset divided by current liability. In order to maintain sufficient amount of current asset on hand bank have to maintain this ratio above 1 .

The third constraint is for maintaining the Current Liability Ratio. This ratio compares current liability with the Equity. This ratio indicates the burden of short term obligation. And banks must have to set a upper cap to control this burden of short term obligations.

The fourth constraint is for maintaining the borrowing ratio. Borrowing ratio is simply the total deposit divided by borrowed funds. The higher the borrowing ratio indicates that a larger amount of deposit turnover in the bank's balance sheet, which in turn can create liquidity pressure. So we need to put an upper cap to this ratio.

The fifth constraint depends on loan to deposit ratio. Loan to deposit ratio is simply the ratio of total loan to total deposit. This ratio actually indicates the degree to which a bank supports its core lending business through deposits.

The sixth constraint depends on Leverage ratio. Leverage ratio is the ratio of core capital and total assets. This ratio is for putting a cap on the balance sheet size. The bank has to put a lower cap to this ratio depending on the risk taking behaviour of the bank.

Seventh constraint is based on maintaining the GAP ratio, i.e. the ratio of the rate sensitive assets (RSA) and rate sensitive liabilities (RSL). According to bank this ratio must have a lower cap since bank always want that their RSA must bear a greater ratio with the RSL.

The eighth constraint is investment constraint. Banks have to invest a certain amount of asset to investment.

The ninth constraint is loan constraint. Bank may not put its entire asset to issue loans, banks can only sanctioned total loan up to some percentage of total assets.

The tenth constraint is based on maintaining total duration gap.

The eleventh constraint is based on the convexity measures.

The twelfth constraint is the basic rules of the bank's balance sheet that the total assets must be equal to the total liabilities and the shareholder's capital.

The last constraint is the non negativity constraint of the assets side as well the liability side.

We will now try to fit a numerical example with this asset liability optimization model.

\section{MATHEMATICAL ANALYSIS}

In this section first we will discuss about weighted sum method and then fuzzy programming techniques considered in this paper to solve a Multi-Objective Non-Linear Programming (MONLP) problem.

\subsection{Weighted sum (WS) method}

The most common approach to solve a multi-objective 
optimization problem is weighted sum (WS) method. Using this weighted sum method a multi-objective problem (MOP) is converted into a single objective optimization problem by help of convex combination of objectives.

Let a subset $\mathrm{X}$ of $R^{p}$ and $\mathrm{n}$ functions $f_{k}: X \rightarrow R$ for $k=$ $1,2, \ldots \ldots, p$ are given. The MOP is defined as follows:

$$
\min _{x \in X} F(x)=\left(f_{1}(x), f_{2}(x), \ldots \ldots \ldots, f_{p}(x)\right)
$$

where, $F: X \rightarrow R^{p}$ is the objective function vector and $X=$ $\left\{x=\left(x_{1}, x_{2}, \ldots, x_{n}\right) \in R^{n}\right\}$.

Finally the WS method solves the following scalar optimization problem.

$$
\begin{gathered}
F(w)=\min _{x \in X} \sum_{k=1}^{p} w_{k} f_{k} \\
\text { subject to } \sum_{k=1}^{p} w_{k}=1, \text { where } w_{k} \geq 0, \text { for } k \\
=1,2, \ldots, p
\end{gathered}
$$

One thing we shall have to keep in mind that it will not be possible to get points on non-convex portions of the Pareto optimal set in the criterion space using WS method.

\subsection{Multi-objective non linear programming (MONLP) problem}

We shall consider a Multi-Objective Non-Linear Programming (MONLP) in vector minimization problem form as given below:

$$
\begin{gathered}
\text { Minimize } w(x) \\
=\left[w_{1}(x), w_{2}(x), \ldots \ldots \ldots \ldots \ldots \ldots, w_{k}(x)\right]^{T} \\
\text { subject to } x \in X=\left\{x \in R^{n}: v_{j}(x) \leq \text { or }=\text { or } \geq\right. \\
\left.b_{j} \text { for } j=1, \ldots \ldots \ldots, m ; x \geq 0\right\}, \text { and } l_{i} \leq x_{i} \leq u_{i} \\
(i=1,2, \ldots \ldots \ldots, n)
\end{gathered}
$$

One of the most efficient methods to deal with a multiobjective programming problem is Fuzzy Programming technique; it was first established by Zimmermann.

\subsection{Fuzzy programming techniques for a MONLP}

In order to solve a MONLP (24) we shall have to follow the following steps.

Step 1: Considering each of the objectives at a time, solve the MONLP as a single objective programming problem ignoring the others. The solutions obtained in these steps are termed as ideal solutions.

Step 2: To find the corresponding values for each of all the objectives at each solution derived from previous step. With these values of all objectives at each ideal solution, the pay-off matrix can be formulated as follows:

$$
\begin{gathered}
w_{1}(x) w_{2}(x) \ldots w_{k}(x) \\
x^{1} \\
x^{2} \\
\ldots \\
x^{k}
\end{gathered}\left[\begin{array}{l}
w_{1}^{*}\left(x^{1}\right) w_{2}\left(x^{1}\right) \ldots \ldots w_{k}\left(x^{1}\right) \\
w_{1}\left(x^{2}\right) w_{2}^{*}\left(x^{2}\right) \ldots \ldots w_{k}\left(x^{2}\right) \\
\ldots \ldots \ldots \ldots \ldots \ldots \ldots \ldots \ldots \ldots \ldots \ldots \\
w_{1}\left(x^{k}\right) w_{2}\left(x^{k}\right) \ldots \ldots \ldots w_{k}^{*}\left(x^{k}\right)
\end{array}\right]
$$

Here $x^{1}, x^{2}, \ldots \ldots \ldots \ldots \ldots, x^{k}$ are the ideal solutions of the objectives $w_{1}(x), w_{2}(x), \ldots \ldots \ldots, w_{k(x)}$ respectively.

So $U_{r}=\max \left\{w_{r}\left(x^{1}\right), w_{r}\left(x^{2}\right), \ldots \ldots, w_{r}\left(x^{k}\right)\right\}$, and

$$
L_{r}=w_{r}^{*}\left(x^{r}\right)
$$

Here $L_{r}$ and $U_{r}$ are lower and upper bounds of the $r$ th objective function $w_{r}(x)$ for $r=1, \ldots, k$.

Step 3: Using aspiration levels of each objective of the MONLP (24) may be written as follows:

Find $x$ so as to satisfy:

$$
w_{r}(x) \widetilde{\leq} L_{r}(r=1,2, \ldots \ldots \ldots, k), x \in X
$$

Here objective functions of (24) are considered as fuzzy constraints. This type of fuzzy constraints can be quantified choosing a corresponding membership function

$$
\begin{aligned}
\mu_{r}\left(w_{r}(x)\right)=\left\{\begin{aligned}
0 \quad \text { if } w_{r}(x) \geq U_{r}(x) \\
d_{r}(x) \quad \text { if } L_{r}(x) \leq w_{r}(x) \leq U_{r}(x) \\
1 \text { if } w_{r}(x) \leq L_{r}(x)
\end{aligned}\right. \\
\text { for } r=1,2, \ldots \ldots \ldots, k
\end{aligned}
$$

Here $d_{r}(x)$ is a strictly monotone decreasing function with respect to $w_{r}(x)$.

Having elicited the membership functions (as in (26)) $\mu_{r}\left(w_{r}(x)\right)$ for $r=1,2, \ldots \ldots, k$, a general aggregation of the form

$$
\mu_{\widetilde{D}}(x)=\mu_{\widetilde{D}}\left(\mu_{1}\left(w_{1}(x)\right), \mu_{2}\left(w_{2}(x)\right), \ldots \ldots \ldots, \mu_{k}\left(w_{k}(x)\right)\right)
$$

is introduced.

So a fuzzy multi-objective decision making problem can be defined as

$$
\begin{aligned}
& \text { Maximize } \mu_{\widetilde{D}}(x) \\
& \text { subject to } x \in X
\end{aligned}
$$

Then fuzzy decision (By Bellman and Zadeh) based on minimum operator by Owusu and Alhassan [18] the problem (25) will take the form

$$
\begin{gathered}
\text { Maximize } \lambda \\
\text { subject to } \mu_{r}\left(w_{r}(x)\right) \geq \lambda, \\
\text { for } r=1,2, \ldots, k \\
x \in X \text { and } 0 \leq \lambda \leq 1
\end{gathered}
$$

This is known as Fuzzy Non-Linear Programming problem (FNLP)

And fuzzy decision based on convex operator (Peng and Chen) [19] the problem (25) will take the form:

$$
\begin{gathered}
\text { Maximize } \sum_{r=1}^{k} \mu_{r}\left(w_{r}(x)\right) \\
\text { Subject to } 0 \leq \mu_{r}\left(w_{r}(x)\right) \leq 1, \\
\text { for } r=1,2, \ldots, k \text { and } x \in X
\end{gathered}
$$

This is known as Fuzzy Additive Goal Programming problem (FAGP)

Step 4: Solve (28) and (29) to get the Pareto Optimal solutions. 


\subsection{Weighted fuzzy non-linear programming (WFNLP)}

Concerning the relative importance of each of the objective functions $w_{r}(x)$, decision maker prefer positive weights $\alpha_{i}$ for $r=1,2, \ldots, k$. these weights in normalized form will be considered by taking $\sum_{i=1}^{k} \alpha_{i}=1$.

Then considering normalized weights, the fuzzy non-linear programming problem (28) becomes:

$$
\begin{gathered}
\text { Maximize } \lambda \\
\text { subject to } \alpha_{r} \mu_{r}\left(w_{r}(x)\right) \geq \lambda \text {, for } r=1,2, \ldots, k \\
x \in X \text { and } 0 \leq \lambda \leq 1 \\
\text { where } \sum_{r=1}^{k} \alpha_{i}=1
\end{gathered}
$$

\subsection{Weighted fuzzy additive goal programming (WFAGP)}

Concerning the relative importance of each of the objective functions $w_{r}(x)$, decision maker prefer positive weights $\alpha_{i}$ for $r=1,2, \ldots, k$. these weights in normalized form will be considered by taking $\sum_{i=1}^{k} \alpha_{i}=1$.

Then considering normalized weights, the fuzzy non-linear programming problem (29) becomes:

$$
\begin{gathered}
\text { Maximize } \sum_{r=1}^{k} \alpha_{r} \mu_{r}\left(w_{r}(x)\right) \\
\text { Subject to } 0 \leq \mu_{r}\left(w_{r}(x)\right) \leq 1, \\
\text { for } r=1,2, \ldots, k x \in X \\
\text { where } \sum_{r=1}^{k} \alpha_{i}=1
\end{gathered}
$$

Few basic definitions of Pareto optimal solutions are presented below.

\section{Definition (Complete optimal Solution)}

$x^{*}$ is said to be a complete solution to the MONLP (24) if and only if there exists $x^{*} \in X$ such that $w_{r}\left(x^{*}\right) \leq w_{r}(x)$ for $r=1,2, \ldots, k$ and for all $x \in X$.

But if the objective functions of a multi-objective problems are conflicting in nature, then complete solution does not exist in general and so the condition of Pareto optimality concept is need to be considered and it is defined as follows.

\section{Definition (Pareto optimal Solution)}

$x^{*}$ is said to be a Pareto solution to the MONLP (23) if and only if there does not exist another $x \in X$ such that $w_{r}\left(x^{*}\right) \leq$ $w_{r}(x)$ for $r=1,2, \ldots, k$ and $w_{j}(x) \neq w_{j}\left(x^{*}\right)$ for at least one $j, j \in\{1,2, \ldots, k\}$.

\section{FUZZY PROGRAMMING TECHNIQUE TO SOLVE MULTI-OBJECTIVE ASSET LIABILITY MODEL (MOALM)}

According to Vector Minimization Problem (VMP) the model (1) can be formulated as:

Minimize

$$
\begin{gathered}
\left\{\sum_{i=2}^{4} r_{i} X_{i}(t)-\sum_{j=2}^{4} s_{j} Y_{j}(t)+\left(\begin{array}{c}
X_{1}(t) \\
+X_{5}(t)+X_{6}(t)
\end{array}\right)\right. \\
\begin{array}{c}
Y_{1} \\
\text { Minimize }
\end{array} \\
\left.\left.\sum_{j=1}^{m} D Y_{1}(t)+Y_{5}(t)\right]\right\} \\
\text { Subjected to the same constraints as } 10-22
\end{gathered}
$$

To solve VMP (10) the pay-off matrix is formulated as follows:

$$
\begin{array}{ccc} 
& f(x) & g(x) \\
x^{1} & f^{*}\left(x^{1}\right) & g\left(x^{1}\right) \\
x^{2} & f\left(x^{2}\right) & g^{*}\left(x^{2}\right)
\end{array}
$$

Now the upper bounds $U_{1}, U_{2}$ and lower bounds $L_{1}, L_{2}$ are identified, where $L_{1} \leq f(x) \leq U_{1}$ and $L_{2} \leq g(x) \leq U_{2}$.

For simplicity we have considered linear membership function for the objective functions $f(x)$ and $g(x)$ defined as follows:

$$
\begin{aligned}
& \mu(f(x))=\left\{\begin{array}{cl}
0 & \text { if } f(x) \leq L_{1} \\
\frac{f(x)-L_{1}}{U_{1}-L_{1}} & \text { if } L_{1} \leq f(x) \leq U_{1} \\
1 & \text { if } f(x) \geq U_{1}
\end{array}\right. \\
& \mu(g(x))=\left\{\begin{array}{cl}
0 & \text { if } g(x) \geq U_{2} \\
\frac{U_{2}-g(x)}{U_{2}-L_{2}} & \text { if } L_{2} \leq g(x) \leq U_{2} \\
1 & \text { if } g(x) \geq L_{2}
\end{array}\right.
\end{aligned}
$$

According to step 3, having elicited the above membership functions crisp non-linear problem of (32) is formulated as follows:

Based on FNLP,

$$
\begin{gathered}
\text { Maximize } \lambda \\
\text { subject to } f(x) \geq L_{1}+\lambda\left(U_{1}-L_{1}\right) \\
g(x) \leq U_{2}-\lambda\left(U_{2}-L_{2}\right) \\
\text { The set of all constraints } 10-22 \\
0 \leq \lambda \leq 1 \\
x_{i} \geq 0 \\
i=1,2, \ldots \ldots \ldots, n
\end{gathered}
$$

Based on weighted FNLP (WFNLP),

\section{Maximize $\lambda$}

$$
\begin{gathered}
\text { subject to } f(x) \geq L_{1}+\frac{\lambda}{\alpha_{1}}\left(U_{1}-L_{1}\right) \\
g(x) \leq U_{2}-\frac{\lambda}{\alpha_{2}}\left(U_{2}-L_{2}\right)
\end{gathered}
$$

And the same constraints as $10-22$

$$
\begin{gathered}
0 \leq \lambda \leq 1 \\
\alpha_{1}+\alpha_{2}=1 \\
x_{i} \geq 0, \\
i=1,2, \ldots \ldots \ldots, n
\end{gathered}
$$

Based on FAGP, 


$$
\begin{aligned}
\text { Maximize } & \frac{f(x)-L_{1}}{U_{1}-L_{1}}+\frac{U_{2}-g(x)}{U_{2}-L_{2}} \\
0 & \leq \frac{f(x)-L_{1}}{U_{1}-L_{1}} \leq 1 \\
0 & \leq \frac{U_{2}-g(x)}{U_{2}-L_{2}} \leq 1
\end{aligned}
$$

And the same constraints as $10-22$

$$
x_{i} \geq 0 \text {, }
$$$$
i=1,2, \ldots \ldots \ldots, n
$$

Based on weighted FAGP (WFAGP),

$$
\text { Maximize } \begin{aligned}
\alpha_{1} & \left(\frac{f(x)-L_{1}}{U_{1}-L_{1}}\right)+\alpha_{2}\left(\frac{U_{2}-g(x)}{U_{2}-L_{2}}\right) \\
0 & \leq \frac{f(x)-L_{1}}{U_{1}-L_{1}} \leq 1 \\
0 & \leq \frac{U_{2}-g(x)}{U_{2}-L_{2}} \leq 1
\end{aligned}
$$

And the same constraints as $10-22$

$$
\begin{gathered}
\alpha_{1}+\alpha_{2}=1 \\
x_{i} \geq 0, \\
i=1,2, \ldots \ldots \ldots, n
\end{gathered}
$$

Solving (33), (34), (35), (36) we will get the Pareto optimal solution to the corresponding problem

\section{NUMERICAL ILLUSTRATION}

Here we will take a hypothetical balance sheet to check the validation of our model. The hypothetical data of both the asset and liability sides are given below in Tables 1 and 2 respectively along with their respective interest rate, which we consider as the monthly interest rate of that corresponding asset or liability.

Table 1. The asset of XYZ bank

\begin{tabular}{cccc}
\hline Asset & Sub category of the asset & Amount & Interest rate \\
\hline$X_{1}$ & & 4550 & - \\
$X_{2}$ & & 5500 & $0.18 \%$ \\
$X_{3}$ & $X_{31}$ & & \\
& $X_{32}$ & $?$ & $0.48 \%$ \\
$X_{4}$ & $X_{41}$ & & $0.52 \%$ \\
& $X_{42}$ & $?$ & $0.465 \%$ \\
& $X_{43}$ & $?$ & $0.47 \%$ \\
$X_{5}$ & & $?$ & $0.495 \%$ \\
$X_{6}$ & & 1100 & - \\
\hline
\end{tabular}

The assets under consideration are as follows:

- Cash and balances with central bank: $\mathrm{X}_{1}(\mathrm{t})$.

- Balance with bank and money at call or short notice: $\mathrm{X}_{2}(\mathrm{t})$.

- Investments: $\mathrm{X}_{3}(\mathrm{t})$.

- Loans: $\mathrm{X}_{4}(\mathrm{t})$.

- Fixed Asset: $\mathrm{X}_{5}(\mathrm{t})$.

- Other Asset: $\mathrm{X}_{6}(\mathrm{t})$.

$\mathrm{X}_{3}(\mathrm{t})$ the investment at times $\mathrm{t}$ is further sub divided into two categories. $X_{31}$ is the one month investment and $X_{32}$ is the 1 year investment.

$X_{4}(t)$, the loans at time $\mathrm{t}$ is further sub divided into 3 categories. $X_{41}$ is the 1 month loan, $X_{42}$ is the 6 month loan and $X_{43}$ is the 1 year loan

For the sake of simplicity of the model we just consider that for that particular time span the cash and balances with Reserve Bank of India, balance with bank and money at call or short notice, fixed asset and other asset is of constant amount.

Assets $X_{31}, X_{32}, X_{41}, X_{42}, X_{43}$ are the decision variables of our model.

- $\quad$ Equity capital: Y1(t).

- $\quad$ Reserve and Surplus: $\mathrm{Y}_{2}(\mathrm{t})$.

- Deposit: $\mathrm{Y}_{3}(\mathrm{t})$.

- Borrowings: $\mathrm{Y}_{4}(\mathrm{t})$.

- Other Liabilities: $\mathrm{Y}_{5}(\mathrm{t})$.

$Y_{3}$ the deposit at time $\mathrm{t}$ is further sub-divided into three sub categories, $Y_{31}$ is the deposit for 1 month, $Y_{32}$ is the deposit for 3 month and $Y_{33}$ is the deposit for 1 year.

$Y_{4}$ the borrowings at time $\mathrm{t}$ is further sub-divided into two sub categories, $Y_{41}$ is the bond of 1 year and $Y_{42}$ is the bond of 2 year.

Similarly for the sake of simplicity we consider reserve and surplus as well as the other liabilities are of constant amount for that particular time span. Also the equity capital is considered as a fixed amount.

Table 2. The liability of XYZ bank

\begin{tabular}{cccc}
\hline Liability & $\begin{array}{c}\text { Sub category of the } \\
\text { liability }\end{array}$ & Amount & $\begin{array}{c}\text { Interest } \\
\text { rate }\end{array}$ \\
\hline$Y_{1}$ & & 9000 & - \\
$Y_{2}$ & & 4000 & $0.21 \%$ \\
$Y_{3}$ & $Y_{31}$ & $?$ & $0.09 \%$ \\
& $Y_{32}$ & $?$ & $0.1605 \%$ \\
& $Y_{33}$ & $?$ & $0.1875 \%$ \\
$Y_{4}$ & & & \\
& $Y_{41}$ & $?$ & $0.195 \%$ \\
$Y_{5}$ & $Y_{42}$ & $?$ & $0.235 \%$ \\
\hline
\end{tabular}

Liabilities $Y_{31}, Y_{32}, Y_{33}, Y_{41}, Y_{42}$ are also the decision variables of our model.

\section{Basic relation of the restraints.}

Let us consider $D_{X_{i}}-\mathrm{i}$-th asset's Duration; $D_{Y_{j}}-\mathrm{j}$-th liability's duration; $C_{X_{i}}-\mathrm{i}$-th asset's Convexity; $C_{Y_{j}}-\mathrm{j}$-th liability's Convexity; t- corresponding interval of the interest payment; $m$ - total number of periods for the asset or the liability; $I_{i t} \& I_{j t}$ - respectively the i-th asset's and $\mathrm{j}$-th liability's interest for the t-th period. $r_{i} \& r_{j}$ - Respectively the interest rate for the i-th asset and j-th liability.

$$
\begin{aligned}
& \text { Then } D_{X_{i}}=\sum_{t=1}^{m}\left[t \times I_{i t} /\left(1+r_{i}\right)^{t}\right] / \sum_{t=1}^{m}\left[I_{i t} /\left(1+r_{i}\right)^{t}\right]^{.} \\
& \text {And } D_{Y_{j}}=\sum_{t=1}^{m}\left[t \times I_{j t} /\left(1+r_{j}\right)^{t}\right] / \sum_{t=1}^{m}\left[I_{j t} /\left(1+r_{j}\right)^{t}\right]^{\cdot} \\
& \text { Also } C_{X_{i}}= \\
& \sum_{t=1}^{m}\left[\left(t^{2}+t\right) \times I_{i t} /\left(1+r_{i}\right)^{t}\right] / \sum_{t=1}^{m}\left[I_{i t} /\left(1+r_{i}\right)^{t}\right]^{.} \\
& \text {And } \quad C_{Y_{j}}= \\
& \sum_{t=1}^{m}\left[\left(t^{2}+t\right) \times I_{j t} /\left(1+r_{j}\right)^{t}\right] / \sum_{t=1}^{m}\left[I_{j t} /\left(1+r_{j}\right)^{t}\right]^{.}
\end{aligned}
$$


Table 3. The duration and convexity for the assets of XYZ bank

\begin{tabular}{ccc}
\hline Assets & Duration & Convexity \\
\hline$X_{1}$ & 0 & 0 \\
$X_{2}$ & 0 & 0 \\
$X_{31}$ & 1 & 2 \\
$X_{32}$ & 11.66 & 150.19 \\
$X_{41}$ & 1 & 2 \\
$X_{42}$ & 5.93 & 41.35 \\
$X_{43}$ & 11.23 & 150.462 \\
$X_{5}$ & 0 & 0 \\
$X_{6}$ & 0 & 0 \\
\hline
\end{tabular}

Using the above mentioned formula the duration and convexity corresponding to the given asset and liabilities are given in Tables 3 and 4 .

The duration and convexity corresponding to the asset and the liabilities which are not interest rate dependent is considered to be equal to 0 .

Also since there are some restrictions on balances with bank and money at call or short notice to use it freely or to reinvest it so we consider the duration and convexity this asset to be 0 .
The Pareto optimal solution for the proposed ALM model by FNLP, FAGP and WS (considering equal weight to both the objectives) is given in Table 5 .

Table 4. The duration and convexity for the liabilities of XYZ bank

\begin{tabular}{ccc}
\hline Liability & Duration & Convexity \\
\hline$Y_{1}$ & 0 & 0 \\
$Y_{2}$ & 0 & 0 \\
$Y_{31}$ & 1 & 2 \\
$Y_{32}$ & 3.00 & 11.97 \\
$Y_{33}$ & 12.00 & 153.87 \\
$Y_{41}$ & 11.87 & 153.79 \\
$Y_{42}$ & 23.36 & 578.82 \\
$Y_{5}$ & 0 & 0 \\
\hline
\end{tabular}

Table 5. Result for different methods

\begin{tabular}{llll}
\hline & FNLP & FAGP & WS \\
\hline ROE(Return) & $64.869 \%$ & $64.861 \%$ & $61.16 \%$ \\
DGAP(Risk) & 11.258452 & 0.0446 & 21.26 \\
\hline
\end{tabular}

Table 6. Result for different methods with weights

\begin{tabular}{cccc}
\hline Weights & FNLP & FAGP & WS \\
\hline Weight for $\mathrm{f}(\mathrm{x})=0.2$ & $\mathrm{ROE}=64.8749 \%$ & $\mathrm{ROE}=61.432 \%$ & $\mathrm{ROE}=59.26 \%$ \\
Weight for $\mathrm{g}(\mathrm{x})=0.8$ & $\mathrm{DGAP}=23.0957847$ & $\mathrm{DGAP}=0.01252$ & $\mathrm{DGAP}=18.3587$ \\
Weight for $\mathrm{f}(\mathrm{x})=0.4$ & $\mathrm{ROE}=64.8691 \%$ & $\mathrm{ROE}=63.879 \%$ & $\mathrm{ROE}=60.357 \%$ \\
Weight for $\mathrm{g}(\mathrm{x})=0.6$ & $\mathrm{DGAP}=10.842221$ & $\mathrm{DGAP}=0.0789$ & $\mathrm{DGAP}=20.01252$ \\
Weight for $\mathrm{f}(\mathrm{x})=0.6$ & $\mathrm{ROE}=63.1748 \%$ & $\mathrm{ROE}=64.978 \%$ & $\mathrm{ROE}=61.897 \%$ \\
Weight for $\mathrm{g}(\mathrm{x})=0.4$ & $\mathrm{DGAP}=0.05168$ & $\mathrm{DGAP}=11.2373491$ & $\mathrm{DGAP}=23.045$ \\
Weight for $\mathrm{f}(\mathrm{x})=0.8$ & $\mathrm{ROE}=60.7790 \%$ & $\mathrm{ROE}=65.001 \%$ & $\mathrm{ROE}=63.357 \%$ \\
Weight for $\mathrm{g}(\mathrm{x})=0.2$ & $\mathrm{DGAP}=0.01854$ & $\mathrm{DGAP}=24.512613$ & $\mathrm{DGAP}=27.7621$ \\
\hline
\end{tabular}

The Pareto optimal solution for the proposed ALM model obtained by WFNLP, WFAGP and WS for different weights are given in Table 6 above.

The Pareto optimal solution for the MOALM obtained by FNLP, FAGP and WS method is given in Table 5, where as the solution by WFNLP, WFAGP and WS is given in Table 6 . Here, FNLP method yields more return but FAGP method gives less risk. So FNLP method gives better results for return and FAGP method gives better results for risk. After incorporating weight from WFNLP we have, while the weight associated with the return objective function increases the return obtained gradually decreases while from WFAGP the return associated with greater weight to the return objective function gradually increases. The opposite situation occurs for risk objective function. From WFNLP we have, while increasing the weight associated with the risk objective function the risk obtained increases, whereas from WFAGP while increasing the weight associated with the risk objective function the risk obtained decreases. But the WS method is giving result which is poor in comparison with both the fuzzy based techniques.

And lastly from the above solution tables obtained by FNLP and FAGP we conclude that in weighted FNLP method weight may be effect on directly to the objective functions but in the weighted FAGP method weight may be effect on inversely to the objective function. Also we may conclude that the fuzzy based techniques are more efficient than the non fuzzy based WS method.

\section{CONCLUSIONS}

In this paper we had proposed a multi-objective risk return trade off model for asset liability management of a bank. To check the validation of the model we had considered a hypothetical bank balance sheet. We had used two fuzzy nonlinear programming techniques based on FNLP and FAGP to solve the model and compared the result with the result obtained by solving the model by WS method. Also weights are incorporated on both the objective functions and then the models are solved by WFNLP and WFAGP method. From the result it is clear that fuzzy non-linear programming technique is an efficient technique and may be used in any other financial optimization model also.

We have developed a deterministic model of ALM. Since ALM of banks depends highly on market interest rate, so we may develop this model as a stochastic ALM model also. In future different optimization algorithms such as genetic algorithm, ant-colony optimization etc. can be used to solve this optimization model more efficiently. This will also give rise of some new directions in this field.

\section{ACKNOWLEDGEMENT}

The authors are thankful to Department of Mathematics, University of Kalyani for providing financial assistance through DST-PURSE program and UGC-SAP program. 


\section{REFERENCES}

[1] Chambers, D., Charnes, A. (1961). Inter-temporal analysis and optimization of bank portfolios. Management Science, 7(4): 393-410. https://doi.org/10.1287/mnsc.7.4.393

[2] Cohen, K.J., Hammer, F.S. (1967). Linear programming and optimal bank asset management decisions. The Journal of Finance, 22(2): 147-165. https://doi.org/10.2307/2325551

[3] Robertson, M. (1972). A Bank Asset Management Model. S. Eilon and T.R. Fowkes (Eds.). Applications of Management Science in Banking and Finance. Gower Press. Epping. Essex, 149-158.

[4] Lifson, K.A., Blackman, B.R. (1973). Simulation and optimization models for asset deployment and funds sources balancing profit liquidity and growth. Journal of Bank Research, 4(3): 239-255.

[5] Fielitz, B.D., Loeffler, T.A. (1979). A linear programming model for commercial bank liquidity management. Financial Management, 41-50. https://doi.org/10.2307/3665037

[6] Eatman, J.L., Sealey Jr, C.W. (1979). A multiobjective linear programming model for commercial bank balance sheet management. Journal of Bank Research, 9(4): 227236.

[7] Giokas, D., Vassiloglou, M. (1991). A goal programming model for bank assets and liabilities management. European Journal of Operational Research, 50(1): 48-60. https://doi.org/10.1016/0377-2217(91)90038-W

[8] Kosmidou, K., Zopounidis, C. (2002). An optimization scenario methodology for bank asset liability management. Operational Research, 2(2): 279. https://doi.org/10.1007\%2FBF02936331

[9] Chi, G., Chi, F. (2007). Optimization model of assetliability portfolio considering duration perfect matching. In 2007 IEEE International Conference on Control and Automation, $\mathrm{pp}$

1307-1312. https://doi.org/10.1109/ICCA.2007.4376572

[10] Yang, Z., Xu, W. (2009). Optimization model of assetliability portfolio based on controlling liquidity risk. In 2009 International Conference on Management and Service Science, $\quad$ pp. 1-4.
https://doi.org/10.1109/ICMSS.2009.5303021

[11] Yang, Z., Xu, W. (2009). Optimal model of assets and liabilities management considering interest risk and time structure risk. In 2009 First International Conference on Information Science and Engineering, pp. 4401-4404. https://doi.org/10.1109/ICISE.2009.806

[12] Yan, D., Chi, G., Wu, H. (2009). Assets and liabilities management optimal model based on VaR controlled prepared duration gap. In 2009 International Joint Conference on Computational Sciences and Optimization, $\quad$ 1: 970-974. https://doi.org/10.1109/CSO.2009.234

[13] Wu, H., Chi, G. (2009). Bank assets and liabilities portfolio optimization model based on the dual-gap immunity of the directional duration and directional convexity. In 2009 International Conference on Management and Service Science, pp. 1-6. https://doi.org/10.1109/ICMSS.2009.5301499

[14] Watada, J. (1997). Fuzzy portfolio selection and its applications to decision making. Tatra Mountains Mathematics Publication, 13: 219-248.

[15] Zimmermann, H.J. (1978). Fuzzy programming and linear programming with several objective functions. Fuzzy Sets and Systems, 1(1): 45-55. https://doi.org/10.1016/0165-0114(78)90031-3

[16] Tiwari, R.N., Dharmar, S., Rao, J. (1987). Fuzzy goal programming - an additive model. Fuzzy Sets and Systems, 24(1): 27-34. https://doi.org/10.1016/01650114(87)90111-4

[17] Tang, E., Du, W. (2020). Measuring interest rate risk with embedded option using HPL-MC method in fuzzy and stochastic environment. Journal of Mathematics. https://doi.org/10.1155/2020/7410909

[18] Owusu, F.B., Alhassan, A.L. (2021). Asset-liability management and bank profitability: Statistical cost accounting analysis from an emerging market. International Journal of Finance \& Economics, 26(1): 1488-1502. https://doi.org/10.1002/ijfe. 1860

[19] Peng, X., Chen, F. (2020). Mean-variance asset-liability management with inside information. Communications in Statistics-Theory and Methods, 1-22. https://doi.org/10.1080/03610926.2020.1772982 